\title{
A ATUAÇÃO DO DISCURSO CRIMINOLÓGICO NAS POLÍTICAS PÚBLICAS FRENTE AO ESTADO MODERNO*
}

\author{
Eduardo Tedesco Castamann ${ }^{1}$ \\ Letícia da Silva Nigris ${ }^{2}$
}

\section{RESUMO}

Com o objetivo de analisar discurso criminológico em relação à possibilidade de fomento ou gestão de políticas criminais, se delineia o campo de atuação desse discurso com a revisitação da cultura política-estatal. Com sucinta apresentação de conceitos políticos e contornos de política criminal, se debate sobre a possibilidade de atuação criminológica crítica de dentro, ou ao menos próximo, do campo político. Emerge, então, a possibilidade desse contato se dar através de um discurso chamado de realismo crítico, que busca compreender o delito ontologicamente e trabalhar com esse fenômeno junto ao corpo político na criação de políticas criminais.

Palavras-chave: Criminologia; Estado Liberal; Políticas Criminais; Realismo crítico; Sistema Penal.

\section{THE ACTION OF CRIMINAL DISCOURSE IN PUBLIC POLICIES AGAINST THE MODERN STATE}

\begin{abstract}
With the objective of analyzing criminological discourse in relation to the possibility of fomenting or managing criminal policies, the field of action of this discourse is outlined with the revisiting of the political-state culture. With a brief presentation of political concepts and contours of criminal policy, there is debate about the possibility of critical criminological action from within, or at least near, the political field. The possibility of this emerges then through a critical realism, which seeks to understand the crime ontologically and to work with this phenomenon together with the political body in the creation of policies.
\end{abstract}

Keywords: Criminology; Liberal State; Criminal Policies; Critical Realism; Penal System.

\section{INTRODUÇÃO}

\footnotetext{
* Este texto é fruto de conclusões parciais do trabalho no Projeto de Pesquisa "Estado de direito, Sistemas de justiça e crítica jurídica: horizontes de uma nova política”, vinculado ao Programa de Pós-Graduação/Mestrado em Direito da Universidade de Passo Fundo (UPF-RS).

${ }^{1}$ Mestrando em Direito no Programa de Pós-Graduação da Universidade de Passo Fundo (UPF-RS); especialista em Direito Penal e Processo Penal - IMED; Integrante do Projeto de Pesquisa "Estado de direito, Sistemas de justiça e crítica jurídica: horizontes de uma nova política" (UPF-RS); Advogado; e-mail: ecastamann@gmail.com

${ }^{2}$ Mestranda em Direito no Programa de Pós-Graduação da Universidade de Passo Fundo (UPF-RS); especialista em Direito Empresarial - IMED; Integrante do Projeto de Pesquisa "Estado de direito, Sistemas de justiça e crítica jurídica: horizontes de uma nova política” (UPF-RS); Advogada; e-mail: leticianigris@ hotmail.com
} 
O presente trabalho se limita a revisitar aspectos gerais do Estado e das políticas públicas, bem como esboçar a possibilidade, ou não, de influência da criminologia na formação de políticas criminais, especificamente em relação às políticas de segurança pública, como modo de efetivação do direito social à segurança por parte do Estado.

A Constituição Federal de 1988 consagrou os direitos sociais como fundamentais, tendo o constituinte alocado tais direitos dentro do título respectivo (Título II "Dos Direitos e Garantias Fundamentais", mais precisamente no art. $6^{\circ}$ ). Como tais, os direitos sociais (chamados também pela maioria da doutrina de direitos de segunda geração) demandam que o Estado atue positivamente, ou seja, exige que sejam tomadas providências estatais para a criação ou manutenção de órgãos e procedimentos indispensáveis para que sejam efetivados. Essa atuação positiva se dá, primeiramente, no âmbito da formação e adoção de políticas públicas adequadas aos fins que se destinam, essencialmente pelas casas executiva e legislativa.

A segurança, tal qual como esculpida no art. $6^{\circ}$, do Texto Magno, como um direito social, é também acondicionada nesses termos, por meio de políticas estatais que gerem e norteiam órgãos, recursos e procedimentos para que a sociedade possa ter efetivamente a prestação do referido direito fundamental. Não se nega que tal direito não vem sendo prestado, muito menos os problemas políticos do país, contudo, não se pode furtar do questionamento: qual a possibilidade ou necessidade de um discurso criminológico proativo na formação ou gestão das políticas de segurança pública?

A partir de uma pesquisa bibliográfica, se objetiva com o presente estudo revisitar as transformações básicas do Estado moderno, principalmente no que tange à função de prover a segurança e manter a ordem, bem como delimitar conceitos atinentes às políticas públicas. Ao final, em evidente plano dialético, confrontar dois posicionamentos acerca da utilidade política do discurso criminológico.

\section{O ESTADO (NEO)LIBERAL E O DEVER - FUNÇÃO - DE SEGURANÇA}

A tradição liberal não reconhece que nenhuma sociedade opera sem violência, ainda que de forma simbólica, e que está imbricada, mesmo no modelo estatal, no tecido das relações sociais e políticas. Desde a Primeira Guerra Mundial o progresso da violência pelo e 
no Estado e sociedade é particularmente notável, inclusive nos Estados mais "fortes e estáveis. (HOBSBAWM, 2007, P. 125)

Hobsbawm refere que a convicção ideológica, desde 1914, domina os conflitos, internos e internacionais, o que de certa forma confere um aspecto moral à violência em seu nome. No entendimento do autor a ascensão da barbárie não é causada por uma certa banalização da violência, mas sim em razão do câmbio de valores morais por "imperativos superiores. (2007, p. 127-128)

O indivíduo, leciona Wolkmer, "enquanto realidade histórico-social, tende a criar e a desenvolver, no contexto de um mundo natural e de um mundo valorativo, formas de vida e de organização societária" (1995, p. 61). Em dado período e sociedade, as estruturas sociais podem ser visualizadas dentro de diferentes níveis, na relação com a natureza, nos mecanismos de produção e no desenvolvimento de forças culturais, ideológicas e políticas. É possível, então, partir da premissa de que o ser humano tende a se associar e isso é requisito fundamental para compreender o fenômeno estatal. (WOLMER, 1995, p. 61-62)

A doutrina tradicional aponta que a origem do Estado poderia ser resumida em três teorias. A teoria da origem familiar, que se dividiria em duas correntes, a patriarcal e a matriarcal, de fundo mais bíblico - com a concepção de um casal originário, tendo o Estado como um desenvolvimento da tribu, que se trataria da união de diversas famílias. Em segundo, temos a teoria da origem patrimonial, que, segundo alguns, evidenciada por Platão, entende o Estado como a reunião das profissões econômicas. Por fim, a teoria da força, que compreende a origem violenta do Estado. (MALUF, 1991, p. 53-57)

A teoria da força, balizada por fatos históricos, considera que a origem do Estado é marcada por lutas, guerras e conflitos violentos, bem como tem (o Estado) como princípio a organização da força e de dominação social. Mesmo em um entendimento mais racional, é a força que promove a unidade estatal, estabelecendo o direito e a justiça, com base no interesse social. (MALUF, 1991, p. 56-47)

Partindo de uma outra perspectiva, Gorczesvski também entende que o surgimento do Estado está ligado intimamente à violência. A instituição estatal teria surgido da imposição, pela força, de um grupo sobre outro. O que, futuramente, com o advento da globalização e o rompimento de barreiras físicas, foi superado por forças externas econômicas. (2010, p. 35-47) 
Englobando as teorias mais tradicionais - consideradas aqui como complementares e não excludentes entre si - é possível delimitar que o Estado como uma estrutura sistêmica de forças que se unem por ocasião de parentesco inicialmente, e, posteriormente, em razão da necessidade de organização social, seja em razão da segurança, seja por motivos econômicos.

O Estado Moderno, erigido sob a Revolução Burguesa de 1789, é suficiente para delimitar o presente estudo, sendo que o Estado Absolutista, de Hobbes, tido como sua primeira versão, não interessa para o desenvolvimento do trabalho. Importante destacar que, conforme leciona Hobsbawm, a partir da referida revolução o chamado Terceiro Estado teve sucesso contra o domínio do clero e da nobreza, tendo a burguesia sido vitoriosa na implementação de um Estado na sua concepção liberal (2014, p. 108).

Leciona Streck, sobre a Revolução Francesa, que,

Na virada do século XVIII, entretanto, essa mesma classe não mais se contentava em ter o poder econômico; queria, sim, agora, tomar para si poder político, até então privilégio da aristocracia, legitimando-a como poder legal-racional, sustentado em uma estrutura normativa a partir de uma "Constituição" - no sentido moderno do termo - como expressão jurídica do acordo político fundante do Estado. (2008, p. 51)

A maior influência revolucionária, sem dúvida, foi da teoria contratualista de Rousseau, que, em termos gerais, reconhecia a legitimidade do poder pela vontade geral, que produz um "corpo moral e coletivo" formador do Estado. Esse corpo indivisível se traduz no pacto social proposto pelo referido autor. Logo, a comunhão das vontades individuais configuraria a cessão dos direitos de propriedade ao Estado, pelo contrato social, restando o último como depositário do bem público, justificando a ingerência do Estado na defesa da própria propriedade. (ROUSSEAU, 2008, p. 29-39).

O contratualismo econômico teve, em Rousseau, a determinação incisiva, complexa e difusa, na medida em que, influenciando diretamente a Revolução Francesa, acentua, como ponto basilar, os chamados direitos e as garantias naturais da pessoa humana. A base da sociedade não está exatamente numa natureza boa ou egoísta, mas em uma volonté génèrale que expresse o livre acordo de direitos naturais e individuais por direitos civis. O poder que representa esta vontade geral se constitui numa instituição (Estado) moral e política que dá execução às decisões do todo. (WOLKMER, 1995, p. 64) 
Muito embora na obra de Rousseau se vislumbre que a vontade geral deveria nortear a atuação estatal a fim de atingir os objetivos do próprio Estado (bem comum), sendo que o próprio autor conceitua soberania como “exercício da vontade geral” (2008, p. 43), é evidente a influência desses valores (de proteção à propriedade) nas Constituições, especialmente na brasileira, no que tange ao direito social de segurança.

Evidentemente, o Estado Moderno, erigido sob a Revolução Liberal-Burguesa, possui viés eminentemente calcado na economia. O liberalismo, como uma teoria antiestatal, que tem como valor maior a liberdade individual, relega ao Estado tão somente a função de garantir a segurança e a ordem, a fim de que as vontades individuais possam ser exercidas livremente, especialmente no mercado, que se organizaria por si só. (STRECK, 2008, p. 6061)

A concepção não intervencionista do Estado liberal ao correr dos anos deixou de ser àquela inicialmente tida quando da Revolução de 1789. Passou-se a verificar que o perigo à propriedade não advinha mais do Estado e suas instituições, mas sim da própria sociedade. (BOBBIO; MATEUCCI; PASQUINO, 1998, p. 699-702)

\begin{abstract}
O Liberalismo lutara fundamentalmente pelas liberdades de (isto é, de religião, de palavra, de imprensa, de reunião, de associação, de participação no poder político, de iniciativa econômica para o indivíduo), e conseqüentemente reivindicara a não interferência por parte do Estado e a garantia para estes direitos individuais, civis e políticos. O enfoque atual é orientado para as liberdades do ou da (isto é, da necessidade, do medo, da ignorância), e para atingir estas finalidades implícitas na lógica universalista do Liberalismo renunciou-se ao dogma da não-intervenção do Estado na vida econômica e social. (BOBBIO; MATEUCCI; PASQUINO, 1998, p. 702-703)
\end{abstract}

Tem-se a partir de então uma mitigação da noção de Estado mínimo, o que ocasionou uma certa dúvida quanto à continuidade do próprio liberalismo. Ou, ainda, pelo contrário, se isso não seria o abandono de um Estado não interventor a condição de sobrevivência dos valores liberais, com o que está baseado o atual capitalismo. (STRECK, 2008, p. 64)

A opção por um Estado maior, notadamente, no aspecto econômico, encontra respaldo na teoria keynesiana, que defende que a falta de intervenção estatal no mercado 
ocasiona instabilidade e lentidão no crescimento econômico, sendo necessária a regulação estatal, o que asseguraria, inclusive, a dominação do capital. (FEIJÓO, 2002, p. 13)

É inegável que, mesmo com a guinada liberal de um Estado negativo para um Estado positivo, os valores liberais de proteção à propriedade permaneceram - e permanecem incólumes como função do Estado de prover segurança e manter a ordem. Isto é, não há novidade que o bem comum seja traduzido na consecução dos objetivos econômicos, inclusive com influência supraestatal, relegando-se ao Estado a manutenção da paz social à serviço do mercado.

Conforme refere Rosanvallon, citando Humboldt,

O princípio-chave de Humboldt é que "o Estado não deve imiscuir-se em nada do que não concerne exclusivamente à segurança (p. 53). A segurança é de fato a única coisa que o homem isolado, entregue a suas próprias forças, não pode obter por si mesmo. Humboldt volta, assim, à definição clássica do Estado-protetor: "A manutenção da segurança, contra os inimigos externos ou contra as perturbações internas, é o objetivo que o Estado se deve propor (p. 62-63). (1997, p. 58)

Wolkmer, em análise mais acurada e próxima à realidade brasileira, refere que o caso dos Estados Latino-americanos é ainda mais preocupante. Diante de um capitalismo tardio e a falta de uma "sociedade burguesa estratificada", bem como a condição periférica destes Estados, emergiu, no seio das elites burocráticas militar e cível, uma onda conservadora que ainda permite um controle oligárquico, de influência colonial, calcado na proteção da propriedade e do capital. Aduz ainda o autor, que as instituições jurídicas e políticas representam essa herança colonial, burocrática e patrimonialista, de viés liberal-individualista, que protegem o interesse do capital e a propriedade privada. (2008, p. 13-20)

Com a evolução do Estado moderno e a "gradativa absorção da vida social pelo estado", bem como a partir do fortalecimento dos movimentos organizados, principalmente sindicatos de trabalhadores e partidos operários, houveram maiores conquistas na esfera social e, consequentemente, maior intervenção social do Estado. Tem-se o surgimento do welfare state. (SCHMIDT, 2007, p. 1990)

Conforme refere Schmidt, o modelo do Estado Social tornou-se referência mundial no que tange às políticas sociais, tendo influenciado inúmeras Constituições. O Estado- 
Providência era amplamente aceito, inclusive pelas elites econômicas em razão de um maciço crescimento da economia e da expansão do mercado. Contudo, um Estado maior dependia de maiores receitas e sempre se colocava em xeque a elevada carga tributária. (2007, p. 1992)

Ao contrário do que já foi demonstrado, de que o Estado Social viria para assegurar a continuidade do capitalismo (conforme Keynes), Rosanvallon, refere que o EstadoProvidência está imbricado com um compromisso social, de forma implícita ou explícita, baseado em uma ideia social-democrata. No caso, tal compromisso promoveria a paz social entre as classes patronais e operárias, sendo que a última não contestaria as relações de produção postas em contrapartida de um Estado redistributivo (de renda) e da existência de acordos sociais (1997, p. 41-42)

É nítida a crise atual, principalmente no que tange à concretização dos direitos sociais. Partindo de uma perspectiva um pouco diversa, Gorczesvski remonta o Estado a partir da violência. Refere que a instituição social do Estado surgiu da imposição, pela força, de um grupo sobre outro. Força essa que com o tempo passa a ser legalizada e institucionalizada. Ocorre que com o advento da globalização, e o rompimento de barreiras territoriais, o Estado se tornou impotente para controlar e lidar com as forças econômicas externas, ficando a mercê delas e, consequentemente, deixando em segundo plano seus compromissos sociais, mas nunca o monopólio da força. (2010, p. 35-38)

À guisa de conclusão inicial é possível referir que a atividade Estatal, desde o início da modernidade, está imbricada em uma função inafastável de prover segurança. Tal direito, muito embora positivado como social, apresenta um viés, diante das perspectivas aqui sinteticamente expostas, nitidamente econômico e para a proteção da propriedade e do capital.

Mesmo com as mudanças históricas, o Estado sempre deteve o monopólio da ordem, principalmente, interna - e talvez hodiernamente somente nesse quesito. Por essa razão, não obstante todos os problemas decorrentes do individualismo e do poder das elites econômicas, se faz necessário repensar as políticas públicas de segurança pública e a contribuição do direito para buscar melhores resultados nas suas consecuções. Importando destacar que o compromisso social é muito mais amplo do que o plano de estudo proposto.

\section{POLÍTICAS PÚBLICAS E A FORMAÇÃO DAS POLÍTICAS CRIMINAIS}


A presença do Estado ocorre, além de outras formas não abordadas aqui, pela adoção de políticas públicas, sendo que, tais, para efetivação dos direitos sociais, aponta Schmitd, devem ser observadas à luz dos processos e instituições que compõe o corpo político do Estado, assim como este, por não ter um fim em si mesmo, não pode ser visto isoladamente tampouco (2007, p. 1988).

Conforme leciona Schmidt, é de suma importância compreender as políticas públicas, tendo em vista que a atividade estatal se apresenta de forma cada vez mais complexa, e que os problemas sociais não comportam mais o simplismo, muito menos apenas a boa vontade política, o que faz com que se analise com mais afinco os resultados, com uma crescente importância sobre a maneira com que as decisões são tomadas e que técnicas são viáveis para solução das questões sociais. Para tanto, o referido autor apresenta três dimensões da política: a ordem do sistema político (polity), os processos que compõe esse sistema (politics) e os resultados substanciais das políticas públicas (policy). Frisa Schmidt que "As relações entre polity, politics e policy são permanentes e as influências são recíprocas", eis que "O arcabouço institucional, os processos e os resultados estão sempre imbricados". (2008, p. 2307-2311)

Outros pontos que merecem destaque, sem o aprofundamento merecido, antes de qualquer avanço é a tipologia das políticas, suas fases, bem como a abordagem metodológica colocada por Schmidt.

Quanto à tipologia - não obstante estarmos tratando aqui de política social - podem ser citadas as distributivas ("distribuição de recursos da sociedade a regiões ou segmentos sociais específicos"), redistributivas ("redistribuição de renda"), regulatórias ("regulam e ordenam, mediante ordens, proibições, decretos, portarias") e constitutivas ou estruturadoras (“definem procedimentos gerais da política”). (2008, p. 2313-2135)

Schmidt ainda relaciona que as políticas públicas devem ser analisadas em suas cinco fases, quais seja, a de percepção e definição dos problemas, a de inserção na agenda política, a de formulação da política pública em si (com adoção de uma alternativa), a de implementação (concretização) e a fase final de avaliação dos resultados, sendo a avaliação eleitoral a principal maneira. (2008, p. 2315-2321) 
Diante da complexidade do fenômeno relacional entre política e políticas públicas, apresenta-se ainda a abordagem sistêmica, que articula todas as variáveis da relação citada e, ainda, promove a inter-relação entre a polity, politics e as policies. Ou seja, considera todos os elementos, bem como o contexto com que estão inseridos. (SCHMIDT, p. 2324-2326)

Delineado, nas concepções de Schmidt, os principais conceitos de políticas públicas, convém delimitar que o ponto de contato do discurso criminológico crítico se dá desde a percepção e definição de problemas, até a fase final de avaliação e dimensão dos resultados (policy) das políticas regulatórias. Isso conjecturado de forma sistêmica, inclusive com o modelo (neo)liberal - ou, ainda, pós-neoliberal, de acordo com alguns - de gestão estatal, dentro do Estado brasileiro. Ocorre que o contato de se dá na forma de discurso crítico não propositivo, conforme se defenderá adiante.

De acordo com Soares, a violência criminal cresce exponencialmente no Brasil há muitos anos, contudo, não há o devido enfrentamento com políticas públicas adequadas, muito menos a alocação de recursos de forma apropriada para alteração do quadro atual. Mais grave que isso, de forma generalizada não há uma gestão séria, sendo que às instituições atuam por vezes sem planejamento algum, sem avaliação e monitoramento, sendo possível referir que sequer há um diagnóstico para embasar qualquer planejamento. (2006, p. 399-400)

Conforme expõe Azevedo e Cifali, desde 1980 a taxa de homicídios vem crescendo no Brasil, chegando, em 2012, a taxa de 29 homicídios por 100 mil habitantes, sendo que a grande maioria dos mortos é afrodescendente, de classes sociais baixas e com pouca escolaridade. Importante frisar que o nível de segurança, no caso do Brasil, está intimamente relacionado a taxa de homicídios (2017, p. 27-30).

Ainda, os mesmos autores apontam o aumento considerável na taxa de encarceramento, sendo que em 1990 era de 61 presos por 100 mil habitantes e em 2013 alcançou o número de 289 presos por 100 mil habitantes, considerando que em julho de 2013 a população carcerária girava em torno de 574 mil pessoas (AZEVEDO; CIFALI, 2017, p. 49$50)$.

É evidente que as políticas criminais não têm sido efetivas ao longo dos anos, eis que a taxas de criminalidade e encarceramento só aumentaram. Razões pelas quais há 
necessidade, além de outras medidas, de revisão conceitual de um discurso criminológico que se encaixe na realidade brasileira quanto às políticas criminais e seus resultados práticos.

Por política criminal, importante destacar de que forma é conceituada. Batista ensina que política criminal se trata do conjunto de princípios que conduzem adequadamente as agendas para ajustar a legislação e às instituições criminais à realidade social. Deveria levar em consideração a rapidez das transições sociais e de seus resultados, bem como das manifestações empíricas provenientes do desempenho das instituições do sistema penal e o avanço das ciências criminais. (2011, p. 33)

Já Delmas-Marty refere que,

A expressão "Política Criminal" foi durante muito tempo sinônimo de teoria e prática do sistema penal designando, conforme a expressão de Feuerbach, "o conjunto dos procedimentos repressivos através dos quais o Estado reage contra o crime". [...]

Entretanto, constata-se hoje que a Política Criminal se desligou tanto do Direito Penal quanto da Criminologia e da Sociologia Criminal e adquiriu um significado autônomo. E quando, em 1975, Marc Ancel cria a revista "Archives de Politique Criminelle", ele frisa de imediato a necessidade de não limitar a Política Criminal apenas ao Direito Penal e propõe que seja considerada como "a reação, organizada e deliberada, da coletividade contra as atividades delituosas, marginais e anti-sociais", empenhando-se em destacar sua dupla característica de "ciência de observação" e de "arte", ou de "estratégia metódica da reação anticriminal". (1992, p. 5)

Em suma, Delmas-Marty, em ampliação da definição Feuerbach, conclui pela definição de política criminal como um "conjunto de procedimentos através dos quais o corpo social organiza as respostas ao fenômeno criminal" (1992, p. 5). Pode-se destacar aqui um posicionamento interessante quanto ao afastamento da criminologia da política criminal, que será explorado adiante.

Ainda sobre conceituação, Larrauri aponta que "La política criminal son las opciones y decisiones que adopta el Parlamento para reducir la delincuencia y organizar el sistema penal" (2015, p. 199). Conjecturando a tomada de decisões acerca das medidas que visam reduzir a criminalidade e gerir todo o sistema criminal.

Divan (2015, p. 47-96), em ampla discussão, apresenta conceito específico de política criminal em que se considera tal como uma gama saberes, estratégias e possibilidades, 
bem como de práticas que conduzem à administração das questões criminais, toda vez que haja justificação para intervenção estatal na sociedade.

Considerando, então, que as políticas públicas são, em seu cerne, decisões em amplo aspecto (considerando desde a identificação do problema até a avaliação do resultado), e que as políticas criminais compreendem decisões que visam dar uma resposta ao fenômeno criminal, seja de forma repressiva ou preventiva, é imprescindível analisar de que forma tais decisões podem ser influenciadas, sempre de forma a melhorar o sistema criminal.

Importante destacar que não serão objeto de análise as nuances do campo político brasileiro, mas tão somente a possibilidade de contribuição do discurso criminológico na formação e gestão da política criminal.

\section{CRIMINOLOGIA: ENTRE O DISCURSO E A PRÁTICA}

Partindo então da concepção de um Estado liberal, bem como da formação de políticas públicas, especificamente as criminais, questiona-se a possibilidade/necessidade de contribuição do discurso criminológico para a formação de pautas políticas e de elementos que contribuam com o sistema penal, especificamente no que tange à segurança pública.

Nesse sentido, existem dois posicionamentos a serem verificados à luz dos conceitos e premissas do discurso da criminologia sobre a utilidade desse próprio discurso e suas consequências. $\mathrm{O}$ primeiro ponto seria o reconhecimento da necessidade de manter o discurso criminológico afastado da esfera institucional, o segundo, pelo contrário, perpassa pela possibilidade de uma atuação desde dentro - ou ao menos de perto - do discurso político. Esclarecendo sempre que não se considera a possibilidade de admitir qualquer retrocesso discursivo no âmbito da criminologia (cf. aponta Divan - 2015, p. 101-105), que, em qualquer caso, deve ser pautado pelo viés crítico.

De forma alguma, conforme salienta Albrecht, não se questiona a postura colaborativa do discurso criminológico, contudo, se coloca em questão a relação de associação mais íntima entre a criminologia e o sistema jurídico, que antes do surgimento da teoria crítica - marxista - funcionava apenas como legitimadora de um sistema posto, em evidente Interacionismo Simbólico. (2010, p. 131-136) 
Carvalho, em evidente defesa da primeira posição - de afastamento do ambiente institucional - refere que diante do compromisso com os direitos fundamentais e da evidente adesão das democracias ocidentais ao populismo punitivo, há uma incompatibilidade de atuação conjunta do discurso criminológico com o discurso político (2014, p. 130).

O referido autor defende que a única alternativa possível à criminologia crítica nesse cenário é a desocupação dos espações institucionais e potencialização da crítica, sob pena de se estar legitimando um sistema autoritário ("razão ardilosa", conforme Carvalho - 2014, p. 136). Reconhece que tal negativa de atuação desde dentro pode ser caracterizada por ser imóvel e contraditória à função transformadora da práxis crítica. (CARVALHO, 2014, p. 130131)

No momento em que surgem conflitos insolúveis entre a preservação dos direitos das pessoas e a afirmação do poder estatal, situações em que a razão de Estado se sobrepõe ao respeito aos direitos humanos, a única alternativa possível ao crítico é a desocupação imediata do ambiente institucional, sabendo, contudo, que as práticas intelectuais permitem expor, em forma de denúncia, este tipo de situação. (CARVALHO, 2014, p. 130-131)

A fim de justificar seu posicionamento, e rechaçar a possível imobilidade do discurso, Carvalho ainda refere que “o trabalho acadêmico é, efetivamente, 'atuação' (e 'atuação política')". Isso em razão da origem científica da pesquisa criminológica que não poderia ser confundida com uma atividade meramente teórica. Além da inegável contribuição intelectual na produção cultural. (2014, p. 131)

Diante do que o autor nomeia como gerencialismo gauche - falho, por assim dizer que seria distinto daquele punitivismo de esquerda (que pugna a tutela de direitos através do sistema penal), mas sim de uma esquerda "gerencialista", que faria um uso atuarial, administrativista, fazendo adesão a um discurso em prol da tutela da ordem (CARVALHO, 2014, p. 139).

Aliás, nesse mesmo diapasão adverte Safatle,

[...] quando não é o decisionismo que reina, encontramos na esquerda uma ingenuidade maior, a saber, a crença de que práticas do governo são um conjunto 
neutro de técnicas e técnicos que podem "funcionar bem" quando dirigidos de uma forma adequada. (2016, p. 78)

Contrariamente ao posicionamento de Carvalho - de que a assunção de uma atividade mais próxima ao corpo político contaminaria o discurso crítico - que é nitidamente legítimo, tem-se o que, Anitua (2016, p. 62) conceitua de realismo de esquerda, que se trata de uma maneira de análise criminológica, social e política, que vem em oposição ao discurso mais conservador do liberalismo.

A sugestão de um realismo discursivo de esquerda, conforme propõe Matthews (2014a, p. 28-29) vem de encontro aos discursos dogmáticos, principalmente atuarial, demonstrando, também, a possibilidade e necessidade de estabelecimento de uma relação maior entre atividade teórica e a atividade prática, em diferentes planos, mas especialmente voltada, inclusive, para aqueles que vivem na periferia. Aliás, ensina o autor em outro trabalho (2014b, p. 184) que há necessidade de reconhecimento da realidade, em dado grau ao menos, na percepção do delito, furtando-se de uma manipulação política ou interpretação equivocada, em um chamado exagero ideológico.

[...] el realismo crítico apunta al desarrollo de un enfoque teórico basado en evidencias, comprometido en su aplicación práctica, en especial, sobre las cuestiones que conciernen a la generalidad de los ciudadanos que no son considerados ni como ingenuos, ni como irracionales. Este enfoque teórico también tiene la finalidad de prevenir los obstáculos y peligros de la criminología, tanto idealista (de izquierdas), como empirista, así como superar el pesimismo que se está apoderando de la ciencia criminológica. (MATTHEWS, 2014b, 183)

Esse discurso criminológico - de base crítica e realista - propõe a retomada do campo político, desde dentro, ou ao menos próximo, afastando o discurso neoliberal dominante, de viés conservador e punitivista, que, salienta Matthews (2014b, p. 183), tem imbricado ao seu discurso e corpo teórico a sua própria práxis, o seu próprio corpo político.

Así, mientras el realismo crítico ve la apropiación de la realidad social como una cuestión problemática, poniendo énfasis en la significación de los conceptos y categorias, para de esta manera proveer un cuadro conceptual sobre el que construímos y nos apropiamos de la realidad, los realistas ingênuos (naïve realists) 
tratan, tanto la realidad social em general como el crimen em particular como algo preestabelecido y diretamente accesible. Mientras que el realismo crítico entende el crimen como una construcción social compleja, el realismo naif en sus várias formas - incluídas la criminología administrativa, las criminologías puramente descriptivas y la denominada "ciência" o "ingenería del crimen" - tende a conceptuar el crimen o delito como algo dado por hecho, asumiendo que la principal finalidade de la investigación criminológica radica simplemente en reportar, contar, describir o mapear el crimen y las victimas. (MATTHEWS, 2014b, p. 184-185).

Assim, apresentam-se os dois posicionamentos, ambos que buscam romper com o pragmatismo conservador (de direita) e reacionário, compreendendo o fenômeno criminológico como um problema em si e efetivamente real. Contudo, não é possível tão somente perceber o delito como um fenômeno social, de alguma forma, apartado da realidade, precisa também ser percebido próximo ao corpo político. (DIVAN; CASTAMANN, 2017)

Corrobora-se a posição de Matthews (2014b, p. 196) quanto à possibilidade de um discurso criminológico (crítico e realista) atuante junto ao corpo político na proposição de pautas e análise de políticas criminais, sem se confundir com a legitimação dos interesses ali representados, ou seja, sem abandono do viés crítico. Isso frente à necessidade de que a criminologia engendre também um compromisso político institucional responsável (MATTHEWS, 2014b, p. 207).

\section{CONSIDERAÇÕES FINAIS}

Com efeito, partindo da concepção do Estado moderno liberal resta evidente que as funções estatais, a partir da Revolução Francesa ao menos, ocorrem tão somente com o objetivo inicial de proteção à propriedade e ao modo de produção. Isso em razão de que, inicialmente era o Estado que apresentava maior risco, quando do Estado Absolutista.

Ao longo dos anos, diante do maior envolvimento da sociedade nos assuntos de Estado, a burguesia verificou que o perigo em face da propriedade não advinha mais do Estado, mas sim da própria sociedade. Razão pela qual o Estado mínimo inicial passou a se tornar mais interventor.

Não obstante a isso, mesmo com advento do welfare state, bem como da socialdemocracia, e, consequentemente, com o evidente compromisso social do Estado. As políticas públicas, especialmente as criminais, e mais especificamente ainda as de segurança, foram sempre pautadas pela defesa dos interesses econômicos. Ou seja, a força estatal - ou a 
violência institucionalizada - coligida por conta das políticas criminais é utilizada mais comumente na defesa da propriedade e do capital.

Para compreensão de como isso funciona, Schmidt expôs de forma clara os principais elementos das políticas públicas, bem como sua tipologia e classificação. A par do que interessou ao presente estudo as políticas regulatórias - de cunho social considerando o direito social à segurança.

Para que se tenha efetividade do direito à segurança é imprescindível que se modifiquem os objetivos macroeconômicos - mesmo que velados - do Estado, eis que são as elites, em uma relação simbiótica com a máquina pública, que todavia controlam a política e, logicamente, gerem as políticas públicas para consecução de direitos.

As políticas criminais da mesma forma sofrem com o controle do capital sobre o Estado. Razão pela qual se questiona o afastamento da criminologia, como ciência de estudo do próprio delito - fenômeno que se deveria buscar reduzir proporcionando mais segurança à sociedade - do campo político.

Ao passo de que há o temor de que a aproximação da teoria com a prática criminológica possa ocasionar um gerencialismo, com a legitimação da violência pelo Estado, conforme rege a cartilha liberal-conservadora, mantém-se o crítico afastado da esfera política, limitando-se a criticar - por vezes até de forma vazia - as políticas públicas em suas fases e resultados.

Contudo, há de se considerar que a vida em sociedade exige uma participação efetiva, inclusive da academia, na formação de políticas públicas. No caso da criminologia, o realismo criminológico - dito de esquerda e sempre crítico - se apresenta com uma nova vertente para suprir essa demanda.

A possibilidade de uma atuação junto ao corpo político na formação, gestão e avaliação das políticas estatais de segurança parece ser indispensável para que se obtenham resultados práticos, reais, mais efetivos na prestação do direito social em questão. Isso sem a ocorrência de uma contaminação político-econômica do discurso crítico criminológico que deve se manter firme na persecução de uma política de segurança pública contextualizada com a realidade brasileira a fim de buscar sempre uma maior efetividade do direito. 


\section{REFERÊNCIAS}

ALBRECHT, Peter Alexis. Criminologia - Uma Fundamentação para o Direito Penal. Trad. Juarez Cirino dos Santos. Rio de Janeiro/Curitiba. Lumen Juris/ ICPC, 2010.

ANITUA, Gabriel Ignácio. El realismo de izquierda todavia estaba ahí. In Revista Critica Penal y Poder. n. 11, p. 58-64. Barcelona: Universidad de Barcelona, septiembre, 2016.

AZEVEDO, Rodrigo Ghiringhelli de; CIFALI, Ana Cláudia. Segurança pública, política criminal e punição no Brasil nos governos Lula (2003-2010) e Dilma (2011-2014): mudanças e continuidades. In SOZZO, Máximo (org.). Pós-neoliberalismo e penalidade na América do Sul. São Paulo: Fundação Perseu Abramo, 2017. P. 27-97.

BATISTA, Nilo. Introdução crítica ao direito penal brasileiro. 12 ${ }^{\mathrm{a}} \mathrm{ed}$. Rio de Janeiro: Revan, 2011.

BRASIL. Constituição da República Federativa do Brasil de 1988. Disponível em: < http://www.planalto.gov.br/ccivil_03/constituicao/constituicao.htm>.

BOBBIO, Norberto. MATTEUCCI, Nicola. PASQUINO, Gianfranco. Dicionário de política. Tradução de Carmen C. Varriale Gaetano Lo Mônaco, João Ferreira, Luís Guerreiro Pinto Cacais e Renzo Dini. Brasília: Editora Universidade de Brasília, 1998, p. 699-703.

CARVALHO, Salo de. O “Gerencialismo Gauche” e a crítica criminológica que não teme dizer seu nome. In Revista Direitos e Garantias Fundamentais v. 15, n. 1., p. 125-155. Vitória: FDV, jan./jun. 2014.

DELMAS-MARTY, Mireille. Modelos e movimentos de Política Criminal. Tradução: Edmundo Oliveira. Rio de Janeiro: Revan, 1992.

DIVAN, Gabriel Antinolfi. Processo Penal e Política Criminal. Uma reconfiguração da Justa Causa para a Ação Penal. Porto Alegre: Elegantia Juris, 2015.

; CASTAMANN, Eduardo Tedesco. Realismo crítico, política criminal e dogmática: o papel ativo do discurso criminológico na inovação legislativa e doutrinária. Revista de Criminologias e Políticas Criminais, v. 3, p. 33-48, 2017. Disponível em: http://dx.doi.org/10.26668/IndexLawJournals/2526-0065/2017.v3i2.2368

FEIJÓO, José Carlos Valenzuela. O Estado neoliberal e o caso mexicano. In LAURELL, Asa Cristina (org.). Estado e políticas sociais no neoliberalismo. Tradução de Rodrigo León Contrera. 3. ed. São Paulo: Cortez, 2002.

GORCZEVSKI, Clovis. A educação para os direitos humanos como política pública de combate a violência na sociedade pós-moderna. In: GORCZEVSKI, Clovis (Org.). Direitos Humanos e participação política. Vol. I. Porto Alegre: Imprensa Livre, 2010, p. 35-47. HOBSBAWM, Eric. A era das revoluções, 1789-1848. 34. ed. Rio de Janeiro: Paz e Terra, 2014. P. 97-132.

HOBSBAWM, Eric. Globalização, democracia e terrorismo. Tradução de José Viegas. São Paulo: Companhia das Letras, 2007.

Revista de Criminologias e Políticas Criminais | e-ISSN: 2526-0065 | Salvador | v. 4 | n. 1 | p. 22 - 38 | Jan/Jun. 2018 
LARRAURI PIJOAN, Elena. Introducción a la criminología y al sistema penal. Madrid: Editorial Trotta, 2015.

MALUF, Sahid. Teoria Geral do Estado. 21. ed. rev. e atual. São Paulo: Saraiva, 1991.

MATTHEWS, Roger. Realist Criminology. London: Palgrave Macmillan, 2014a.

Realismo Critico: un análisis estructural in Política Criminal, vol. 9, n.

17, Julio, 2014b, Art. 6, pp. 182-212. Universidad de Talca, Chile. Disponível em: http://www.politicacriminal.cl/index.php?option=com_content \&task=view\&id=45\&Itemid=9 (Acesso em 21 de Junho de 2017).

ROSANVALLON, Pierre. A crise do Estado-providência. Tradução de Joel Pimentel de Ulhoa. Goiânia: Editora da UFG; Brasília: Editora da UnB, 1997.

ROUSSEAU, Jean-Jacques. Do contrato social: princípios de direito político. Tradução de J. Cretella Jr. e Agnes Cretella. 2. ed. rev. da tradução. São Paulo: Editora Revista dos Tribunais, 2008.

SAFATLE, Vladimir. A esquerda que não teme dizer seu nome. São Paulo: Três Estrelas, 2016.

SCHIMIDT, João Pedro. Gestão de políticas públicas: elementos de um modelo pósburocrático e pós-gerencialista. In LEAL, Rogério Gesta; REIS, Jorge Renato. Direitos sociais e políticas públicas: desafios contemporâneos. Tomo 7. Santa Cruz: EDUNISC, 2007. P. 1988-1996.

SCHIMIDT, João Pedro. Para entender as políticas públicas: aspectos conceituais e metodológicos. In LEAL, Rogério Gesta; REIS, Jorge Renato. Direitos sociais e políticas públicas: desafios contemporâneos. Tomo 8. Santa Cruz: EDUNISC, 2008. P. 2307-2333.

SOARES, Luiz Eduardo. Legalidade libertária. Rio de Janeiro: Editora Lumen Juris, 2006.

STRECK, Lenio Luiz. Ciência política e teoria do estado. 6. ed. Porto Alegre: Livraria do Advogado Ed., 2008.

WOLKMER, Antonio Carlos. Repensando a questão da historicidade do Estado e do Direito na América Latina. In WOLKMER, Antonio Carlos; VIEIRA, Reginaldo de Souza (Org.). Estado, política e direito. Criciúma: UNESC, 2008.

WOLKMER, Antonio Carlos. Ideologia, estado e direito. 2. ed. rev. e ampl. São Paulo: Editora Revista dos Tribunais, 1995. 